\title{
HCC burden in Egypt
}

\begin{abstract}
Hepatocellular carcinoma (HCC) is the commonest primary cancer of the liver. Geographical distribution of HCC varies throughout the world with an incidence rate ranging from 2.1 in Central America to 35.5 in Eastern Asia. The burden of HCC has been increasing in Egypt with a doubling in the incidence rate in the past 10years. This may be attributed to high prevalence of HCV in Egypt. Egypt has a high incidence of $\mathrm{HCC}$ about $21 \%$ in cirrhotic Egyptian patients. HCV and HBV infections, diabetes and smoking are the main determinants of HCC development in Egypt. Occult HBV infection may influence the outcome of HCV infection leading to development of HCC. An active surveillance and secondary prevention programs for patients with chronic hepatitis are the most important steps to reduce the risk of HCC.
\end{abstract}

Volume 2 Issue 3 - 2015

\author{
Ehab Abdel Atti \\ Hepatology and Gastroenterology Unit Internal Medicine \\ Department, Menoufia University, Egypt
}

Correspondence: Ehab Abdel-Atti, Hepatology and Gastroenterology Unit Internal Medicine Department, Faculty of Medicine, Menoufia University, Shabin Elkom, Egypt, Email ehab_abdlelatty@hotmail.com

Received: May 13, 2015 | Published: July 9, 2015

Keywords: hepatocellular carcinoma, Hepatitis C virus, chronic liver diseases

Abbreviations: HCC, hepatocellular carcinoma; HCV, hepatitis c virus; $\mathrm{HBV}$, hepatitis B virus

\section{Introduction}

Hepatocellular carcinoma (HCC) is one of the most common cancers worldwide. It is rarely detected early. HCC is the commonest primary cancer of the liver. Hepatocellular carcinoma is one of the 130 major causes of morbidity and mortality in the world. It represents the third leading cause of cancer death in males and the fourth in females with more than 600000 deaths per year. ${ }^{1}$ Geographical distribution of $\mathrm{HCC}$ varies throughout the world with an incidence rate ranging from 2.1 in Central America to 35.5 in Eastern Asia. The burden of HCC has been increasing in Egypt with a doubling in the incidence rate in the past 10years. ${ }^{2}$ There is a geographic correlation between the incidence of HCC and the prevalence of chronic hepatitis B and C, suggesting that these two viral infections are the most important risk factors of HCC worldwide. Co-infection with Hepatitis B virus (HBV) and Hepatitis $\mathrm{C}$ virus (HCV) is associated with a higher risk for developing HCC than either infection alone. ${ }^{3}$ Several risk factors for the development of $\mathrm{HCV}$-associated $\mathrm{HCC}$ have been reported such as aging, gender and alcohol intake. ${ }^{4}$

Egypt has the highest prevalence of $\mathrm{HCV}$ worldwide and has rising rates of $\mathrm{HCC}^{5-7}$ Our retrospective study about risk factors for hepatocellular carcinoma on cirrhotic Egyptian patients ${ }^{8}$ was done on 300 patients with $\mathrm{HCC}$ and 50 patients with chronic liver diseases without $\mathrm{HCC}$ as controls. Prevalence rate of DM and smoking was significantly higher in $\mathrm{HCC}$ cases $(59.3 \%$ and $69 \%$ respectively) than controls ( $38 \%$ and $50 \%$ respectively) $(\mathrm{P}=0.005$ and 0.006 respectively). The prevalence of $\mathrm{HBsAg}$ and $\mathrm{HCV} \mathrm{Ab}$ was significantly higher in HCC cases (18\% and 70\% respectively) than controls (4\% and $40 \%$ respectively) ( $\mathrm{P}=0.02$ and 0.0001 respectively). On multivariate analysis, the risk of HCC development in smokers with HBV or HCV was 4.90 and 8.47 respectively $(\mathrm{OR})(\mathrm{P}=0.0001)$. It was higher than in non-smokers with $\mathrm{HBV}$ or $\mathrm{HCV}(\mathrm{OR}=2.48$ and 4.44 respectively) ( $\mathrm{P}=0.037$ and 0.0001 respectively) and in smokers without HBV or $\mathrm{HCV}(\mathrm{OR}=2.56$ and 2.77 respectively) $(\mathrm{P}=0.01)$. The risk of $\mathrm{HCC}$ development in HBV or HCV positive patients with DM was 3.98 and 9.19 respectively $(\mathrm{OR})(\mathrm{P}=0.001$ and 0.0001 respectively). It was higher than for HBV or HCV positive patients without $\mathrm{DM}(\mathrm{OR}=2.80$ and 4.65 respectively) ( $\mathrm{P}=0.031$ and 0.0001 respectively) and that for $\mathrm{HBV}$ or $\mathrm{HCV}$ negative patients with $\mathrm{DM}(\mathrm{OR}=2.56$ and 2.23 respectively) ( $\mathrm{P}=0.011$ and 0.0001 respectively). A preliminary data from a survey on 1350 Egyptian cirrhotic patients revealed that 289 patients had HCC (21.4\%). Also HCV, HBV and smoking are risk factors of HCC development.

Our study about the prevalence of occult HBV (OBI) among HCV positive Egyptian patients documented that out of 100 chronic HCV patients; only 16 patients (16\%) had OBI. HCC was significantly more common in $\mathrm{OBI} / \mathrm{HCV}$ dually infected (31\%) than HCV monoinfected patients $(7 \%)(\mathrm{P}=0.01)$. On doing multiple logistic regression analysis, $\mathrm{OBI}$ is a risk factor for $\mathrm{HCC}$ in Egyptian $\mathrm{HCV}$ positive patients $(\mathrm{P}=0.04) .{ }^{9}$ Extensive collaborative research was carried out during the last decade to explore independent and combined effects of HBV and HCV and other factors in the etiology of HCC. Although HBV is considered worldwide as a major risk factor for liver cirrhosis and $\mathrm{HCC}$, the prevalence of HBV infection in Egypt has been declining over the last two decades, while HCV has increased. Egypt has possibly the highest $\mathrm{HCV}$ prevalence worldwide around $14 \% .{ }^{10}$ In our previous study, ${ }^{8} \mathrm{HCV}$ positive patients are 211 representing $70 \%$ of the total number of HCC cases, while HBV positive cases are only 54 representing $18 \%$. There is a higher $\mathrm{OR}$ for $\mathrm{HCV}+\mathrm{ve}$ cases compared with those of HBV representing 24.33 and 17.65 respectively. The rising trend of $\mathrm{HCC}$ has been associated with increased prevalence of Hepatitis $\mathrm{C}$ virus (HCV) infection in Egypt. ${ }^{8}$ Moreover, in addition to $\mathrm{HCV}$ and $\mathrm{HBV}$ infections, DM appears to be associated with HCC. ${ }^{11}$ DM increased the risk of HCC development independent of chronic HCV hepatitis and chronic HBV hepatitis as previously described. ${ }^{5,12}$ Previous studies suggest that $\mathrm{HCV}, \mathrm{HBV}$ and DM play an independent role and synergistic effect in liver tumorigenesis. ${ }^{13,14} \mathrm{HCV}$ positive Egyptian cirrhotic patients with diabetes had a higher risk of HCC than those without diabetes. Seronegative individuals with diabetes also had a higher risk of HCC than those without diabetes. ${ }^{8}$

A prominent role of tobacco smoking in the etiology of $\mathrm{HCC}$ can be observed. Such a relationship is due to several chemicals in tobacco smoke metabolized and then activated to be carcinogenic in the live. ${ }^{15}$ Smoking increased the risk of HCC development independent of $\mathrm{HCV}$ and $\mathrm{HBV}$ infections in Egyptian cirrhotic patients. ${ }^{8}$ There was a synergism between HBV and smoking as risk factors for HCC in Egyptian cirrhotic patients. Moreover, smokers with $\mathrm{HBV}+\mathrm{ve}$ have an $\mathrm{OR}$ significantly higher than $\mathrm{HBV}+\mathrm{ve}$ alone or smoking alone $(\mathrm{OR}=$ 
4.90, 2.84 and 2.56 respectively). Franceschi et al..$^{16}$ had demonstrated that tobacco smoking was related to HCC risk and seemed to enhance HCC risk among viral hepatitis patients.

\section{Conclusion}

Egypt has a high incidence of HCC about $21 \%$ in cirrhotic Egyptian patients. HCV and HBV infections, diabetes and smoking are the main determinants of HCC development in Egypt. There is a synergistic effect of many risk factors. An active surveillance and secondary prevention programs for patients with chronic hepatitis are the most important steps to reduce the risk of HCC. Occult HBV infection may influence the outcome of $\mathrm{HCV}$ infection leading to development of HCC. The persistent HBV infection may have a critical role in the development of HCC in HBsAg-negative patients. So, occult HBV should be considered and evaluated by more sensitive PCR among HCV-infected patients.

\section{Acknowledgments}

None.

\section{Conflicts of interest}

Author declares there are no conflicts of interest.

\section{Funding}

None.

\section{References}

1. Hassan MM, Spitz MR, Thomas MB, et al. The association of family history of liver cancer with hepatocellular carcinoma: A case control study in the United States. J Hepatol . 2009;50(2):334-341.

2. Gomaa AI, Khan SA, Toledano MB, et al. Hepatocellular carcinoma: Epidemiology, risk factors and pathogenesis. WorldJGastroenterol. 2008;14(27):4300-4308.

3. Shi J, Zhu L, Liu S, et al. A meta-analysis of case-control studies on the combined effect of hepatitis $\mathrm{B}$ and $\mathrm{C}$ virus infections in causing hepatocellular carcinoma in China. Br J Cancer. 2005;92(3):607-612.

4. Ohata K, Hamasaki K, Toriyama K, et al. Hepatic Steatosis Is a Risk Factor for Hepatocellular Carcinoma in Patients with Chronic Hepatitis C Virus Infection. Cancer. 2004;97(12):3036-3043.
5. Ismail AM, Ziada HN, Sheashaa HA, et al. Decline of viral hepatitis prevalence among asymptomatic Egyptian blood donors: a glimmer of hop. 2009;20(5):490-493.

6. Lehman EM, Wilson ML .Epidemiology of hepatitis viruses among hepatocellular carcinoma cases and healthy people in Egypt: a systematic review and meta-analysis. Int J Cancer. 2009;124(3):690-697.

7. El-Zayadi A, Badran HM, Barakat EM, et al. Hepatocellular carcinoma in Egypt: A single center study over a decade. World J Gastroentero. 2005;11(33):5193-5198

8. Baghdady I, EI-Kaffrawy N, Abd EI-Atti E, et al. Study of the risk factors for hepatocellular carcinoma: effect of their synergism. Journal of American Science. 2013;9(4):211-217.

9. Baghdady I, Shoeib S, Abdelatti E, et al. Occult Hepatitis B Virus infection in Egyptian Hepatitis C Virus positive patients: Prevalence and impact on Hepatocellular Carcinoma development. MMJ. 2011;24(1):197-210.

10. Anwar WA, Khaled HM, Amra HA, et al. Changing pattern of hepatocellular carcinoma (HCC) and its risk factors in Egypt: Possibilities for prevention. Mutat Res. 2008;659(1-2):176-184.

11. Moore MA, Park CB, Tsuda H. Implications of the hyperinsulinaemia diabetes-cancer link for preventive efforts. Eur $J$ Cancer Prev. 1998;7(2):89-107.

12. Donadon V, Balbi M, Ghersetti M, et al. Antidiabetic therapy and increased risk of hepatocellular carcinoma in chronic liver disease. World J Gastroenterol. 2009;15(20):2506-2511.

13. Hassan MM, Hwang LY, Hatten CJ, et al. Risk factors for hepatocellular carcinoma: synergism of alcohol with viral hepatitis and diabetes mellitus. Hepatology. 2002;36(5):1206-1213.

14. Mori M, Hara M, Wada I, et al. Prospective study of hepatitis B and $\mathrm{C}$ viral infections, cigarette smoking, alcohol consumption, and other factors associated with hepatocellular carcinoma risk in Japan. Am J Epidemiol. 2000;151(2):131-139.

15. Lee YC, Cohet C, Yang Y-Ch, et al. Meta-analysis of epidemiologic studies on cigarette smoking and liver cancer. Int $J$ Epidemiol. 2009;38(6):1497-1511.

16. Franceschi S, Montella M, Polesel J, et al. Hepatitis Viruses, Alcohol, and Tobacco in the Etiology of Hepatocellular Carcinoma in Italy. Cancer Epidemiol Biomarkers Prev. 2006;15(4):683-689. 